Article

\title{
Climatology of Passive Microwave Brightness Temperatures in Tropical Cyclones and their Relations to Storm Intensities as Seen by FY-3B/MWRI
}

\author{
Bo Qian ${ }^{1,2} \oplus$, Haiyan Jiang ${ }^{2}$, Fuzhong Weng ${ }^{3, *}$ and Ying $\mathrm{Wu}^{1}$ \\ 1 Key Laboratory of Meteorological Disaster, Ministry of Education (KLME)/ Joint International Research \\ Laboratory of Climate and Environment Change (ILCEC)/Collaborative Innovation Center on Forecast and \\ Evaluation of Meteorological Disasters (CIC-FEMD)/Key Laboratory for Aerosol-Cloud-Precipitation of \\ China Meteorological Administration, Nanjing University of Information Science \& Technology (NUIST), \\ Nanjing 210044, China; bo.qian@nuist.edu.cn (B.Q.); yingwu@nuist.edu.cn (Y.W.) \\ 2 Department of Earth \& Environment, Florida International University, Miami, FL 33199, USA; hajian@fiu.edu \\ 3 Laboratory of Severe Weather, Beijing 100081, China \\ * Correspondence: wengfz@cma.gov.cn; Tel.: +86-010-58994229
}

Received: 19 November 2019; Accepted: 24 December 2019; Published: 1 January 2020

\begin{abstract}
A new database, the tropical cyclones passive microwave brightness temperature (TCsBT) database including 6273 overpasses of 503 tropical cyclones (TC) was established from 6-year (2011-2016) Fengyun-3B (FY-3B) Microwave Radiation Imager (MWRI) Level-1 brightness temperature (TB) data and TC best-track data. An algorithm to estimate the TC intensity is developed using MWRI TB's from the database. The relationship between microwave TB and the maximum sustained surface wind (Vmax) of TCs is derived from the TCsBT database. A high correlation coefficient between MWRI channel TB and Vmax is found at the radial distance 50-100 km near the TC inner core. Brightness temperatures at $10.65,18.70,23.8$, and $36.5 \mathrm{GHz}$ increase but $89 \mathrm{GHz}$ TB's and polarization corrected $\mathrm{TB}$ at $36.5 \mathrm{GHz}\left(\mathrm{PCT}_{36.50}\right)$ and $\mathrm{PCT}_{89}$ decrease with increasing TC intensity. The TCsBT database is further separated into the 5063 dependent samples (2010-2015) for the development of the TC intensity estimation algorithm and 1210 independent samples (2016) for algorithm verification. The stepwise regression method is used to select the optimal combination of storm intensity estimation variables from 12 candidate variables and four parameters $\left(10.65 \mathrm{~h}, 23.80 \mathrm{v}, 89.00 \mathrm{v}\right.$ and $\left.\mathrm{PCT}_{36.50}\right)$ were selected for multiple regression models development. Among the four predictors, $\mathrm{PCT}_{36.50}$ contributes the most in estimating TC intensity. In addition, the errors are lower for estimating 6-h and 12-h future Vmax than estimating the current Vmax.
\end{abstract}

Keywords: tropical cyclones; passive microwave brightness temperature; storm intensities

\section{Introduction}

Meteorological satellites have become an indispensable tool for tropical cyclone monitoring, early warning, and forecasting. In the 1970s, a major advance in tropical cyclones (TC) detection from space came with the deployment of geostationary meteorological satellites. With high-resolution satellite data, scientists at the NOAA Environmental Satellite Service were able to refine techniques to estimate TC intensity. In particular, NOAA scientist, Vernon Dvorak, developed his famous subjective image pattern recognition technique, the Dvorak technique, which was first published over four decades ago [1]. The Dvorak TC intensity analysis and estimation technology uses visible and infrared (VIS/IR) channels and has been widely used over four decades. The original Dvorak algorithm is subjective and dependent on interpretations of TC attributes by different analysts, and therefore, can result in different intensity estimates for the same storm. Analysis results obtained using the Dvorak method for TC 
intensity estimation with geostationary meteorological satellite imagery may, therefore, serve as an important basis for TC intensity analysis. An automatic version of the Dvorak algorithm, the objective Dvorak technique [2] and the advanced Dvorak technique [3,4], have been developed in recent years. However, erroneous judgment in the TC developing stage may create major inaccuracies in the results of the Dvorak method. Accordingly, analysts must take the life stage of a TC into consideration when determining its intensity. In addition, since the Dvorak method involves statistical procedures, analysis of exceptionally rapid intensification or rapid weakening can be difficult [5].

Passive MicroWave (PMW) imagery is available from polar-orbiting satellites, and applications have progressed because of the recent launch of new imagers and the extensions of existing satellite programs such as the GCOM-W Advanced Microwave Scanning Radiometer 2 (AMSR2), Fengyun 3-Series MicroWave Radiation Imager (FY-3/MWRI), and Global Precipitation Measurement Microwave Imager (GPM/GMI). The microwave radiation at longer wavelengths is not sensitive to ice clouds and can, therefore, be linked to surface parameters. Furthermore, PMW imagers can map TC rain-band organization and eyewall development by viewing through non-raining clouds. Similar details cannot be routinely extracted in VIS/IR data because of upper-level cloud obscuration [6,7].

The advantage of PMW observations over VIS/IR data is that the former can penetrate into clouds and precipitation and obtain the information in a lower atmosphere and surfaces. Since the TC intensity (here we use the maximum sustained wind speed as the TC intensity metric) is highly controlled by the upward motion and latent heating which are critical for driving a TC's circulation, rain rate, and moisture content near the storm inner, are good indicators of upward motion and latent heating, therefore, they are highly correlated with TC intensity. PMW observations can provide critical information in estimating TC intensity since their observations are strongly influenced by rain, clouds, and moisture. The center channel frequencies of the PMW imagers available on meteorological satellites typically include 10,19, 23, 37, 85, and $91 \mathrm{GHz}$. Many hurricane intensity estimation studies have been conducted using these PMW sensors. For low-frequency channels, such as 10 and $19 \mathrm{GHz}$, although they have lower spatial resolution, the brightness temperatures (TB) of these channels have higher correlations with TC intensity than high-frequency channels [8] because these lower frequency channels are more sensitive to emission from precipitation that is highly correlated to TC intensity $[9,10]$. As a microwave water vapor absorption frequency, $23 \mathrm{GHz}$ is mainly used to measure the content of water vapor, which is related to TC intensity as well. The $37 \mathrm{GHz}$ channel represents a unique characteristic that can detect a mixed effect from the emission of liquid hydrometeors and scattering of ice cloud upwelling $[10,11]$. The 85 or $91 \mathrm{GHz}$ channels are influenced strongly by the scattering of radiation by ice particles, therefore having an indirect but still good correlation with rain rate over the inner core and TC intensity [12,13]. Spencer [14] and Grody [15] derived the $85 \mathrm{GHz}$ and $37 \mathrm{GHz}$ channel polarization-corrected brightness temperature (PCT) to reduce and correct the ambiguity between low TB due to ice scattering and radiometrically cold sea surface. See Formulas (1) and (2) below:

$$
\begin{gathered}
P C T_{37}=T B_{37 v}+1.18 \times\left(T B_{37 v}-T B_{37 h}\right) \\
P C T_{85}=T B_{85 v}+0.818 \times\left(T B_{85 v}-T B_{85 h}\right)
\end{gathered}
$$

Here $v$ and $h$ subscripts refer to vertical and horizontal polarizations, respectively. Previous studies have found that PCT85 is highly correlated with rain rate and TC intensity [12,13]. Many previous studies have provided the proof-of-concept of using $85 \mathrm{GHz}$ TB's and PMW retrieved rain rates to estimate TC intensity [13,16,17] Recently, Bankert and Tag (2002) [18] developed an automatic TC intensity estimation technique using both the $85 \mathrm{GHz}$ and derived rain-rate imagery from SSM/I data. Jiang et al. (2019) [12] developed a multi-linear regression algorithm to estimate TC intensity using predictors derived from $85 \mathrm{GHz}$ PCT and microwave retrieved rain rate from TRMM TMI data. The detailed error statistics of different TC intensity estimation techniques, including the Dvorak techniques, were summarized in Table 9 of Jiang et al. (2019) [12]. Although it is optimal to use the retrieved rain rate to estimate TC intensity, the PMW retrieval algorithms could have many 
uncertainties, especially for the newly launched FY-3/MWRI program. Therefore, the goal of this study is to develop a new TC intensity objective estimation method by solely using PMW TB's. In this paper, the relations between PMW TB at $10.65 \mathrm{v} / \mathrm{h}, 18.70 \mathrm{v} / \mathrm{h}, 23.80 \mathrm{v} / \mathrm{h}, 36.50 \mathrm{v} / \mathrm{h}, 89.00 \mathrm{v} / \mathrm{h} \mathrm{GHz}$, and PCT 36.50 , and the $\mathrm{PCT}_{89.00}$ in TCs and the corresponding storm intensities were analyzed and an objective multiple regression-based TC intensity estimation method was developed based on FY-3B/MWRI observations. Section 2 describes the data and methods applied in this study. The relationships between FY-3B/MWRI TB and TC intensities are discussed in Section 3.1, Section 3.2 presents the microwave TB distribution characteristics of TCs over a 50-100 km radial annular region. Regression analysis, including stepwise-based optimal parameter selection and multiple linear regression algorithm for TC intensity estimation, is described in Section 3.2.2. The discussion and conclusion are presented in Section 4.

\section{Data and Methodology}

\subsection{The Best-Track Data}

Positions and maximum sustained surface winds of TCs are reported every $6 \mathrm{~h}$ as part of the best-track datasets. Six TC-prone basins are considered in this study: Atlantic (ATL), eastern central Pacific (EPA), northwestern Pacific (NWP), northern Indian Ocean (NIO), southern Indian Ocean (SIO), and South Pacific (SPA). The best-track data of the ATL and EPA basins are obtained from the National Hurricane Center (NHC) [19]. For the other four basins, these data are taken from the U.S. Navy's Joint Typhoon Warning Center (JTWC) (For Data details see the https://www.metoc.navy.mil/jtwc/jtwc. html?western-pacific). A total of 538 storms that reached tropical storm intensity levels or above were identified globally from 2011 to 2016 (Figure 1).

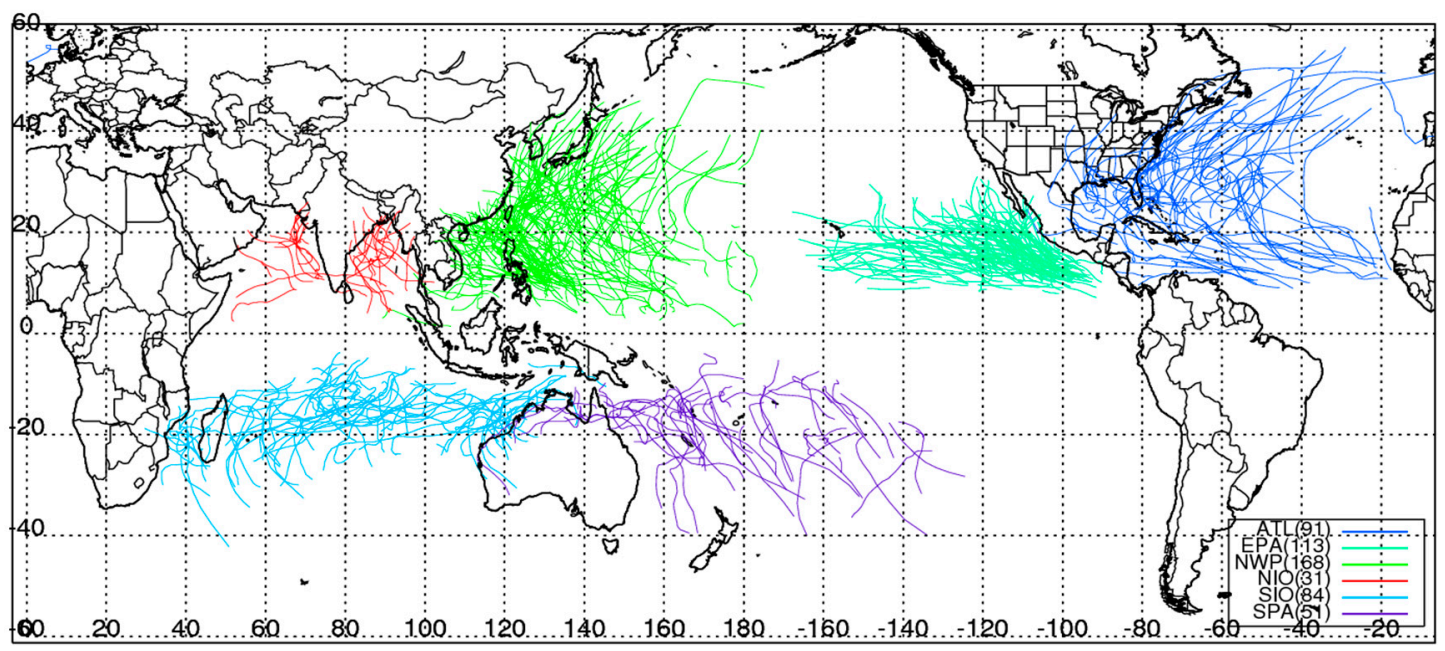

Figure 1. Global tropical cyclones (TC) best tracks in six basins from 2011-2016. TC numbers for each basin are shown in brackets.

\subsection{FY-3B/MWRI Level-1 TB Data}

The FY-3 (FengYun-3) is the second-generation Polar-Orbiting Meteorological Satellite Series of the China Meteorological Administration/National Satellite Meteorological Center (CMA/NSMC). The FY-3B spacecraft was launched on November 4, 2010 (FY-3B/MWRI Sensor details see https://www. wmo-sat.info/oscar/satellites/view/114). An FY-3B/MWRI sensor with 5 channels at 10 frequencies is set to conical scan mode, with a $1400 \mathrm{~km}$ swath width (Table 1). In this study, FY-3B/MWRI level-1 TB data are used from 2011 to 2016. 
Table 1. Fengyun 3-Series MicroWave Radiation Imager (FY-3B/MWRI) descriptions and channel characteristics.

\begin{tabular}{|c|c|c|c|c|c|}
\hline Full name & \multicolumn{5}{|c|}{$\begin{array}{l}\text { Fengyun-3B Micro-Wave Radiation Imager } \\
\qquad \text { (FY-3B/MWRI) }\end{array}$} \\
\hline Scanning technique & \multicolumn{5}{|c|}{$\begin{array}{c}\text { Conical: } 53.1^{\circ} \text { zenith angle, swath width: } 1400 \mathrm{~km} \text {, } \\
\text { sampling points } / \mathrm{scan}=240\end{array}$} \\
\hline Center channel frequency $(\mathrm{GHz})$ & 10.65 & $18.7^{1}$ & 23.8 & 36.5 & 89 \\
\hline Polarization & $\mathrm{V}, \mathrm{H}$ & $\mathrm{V}, \mathrm{H}$ & $\mathrm{V}, \mathrm{H}$ & $\mathrm{V}, \mathrm{H}$ & $\mathrm{V}, \mathrm{H}$ \\
\hline $\begin{array}{l}\text { Ground resolution } \\
\qquad(\mathrm{km} \times \mathrm{km})\end{array}$ & $51 \times 85$ & $30 \times 50$ & $27 \times 45$ & $18 \times 30$ & $9 \times 15$ \\
\hline
\end{tabular}

\subsection{Generation of the FY-3B/MWRI-Based Tropical Cyclones Brightness Temperature (TCsBT) Database}

First, the global TC 6-h best-track data are collected from the NHC and JTWC and interpolated into FY3B/MWRI observation times. Then, TC overpasses are identified if the distance between the TC center and the MWRI swath center is less than $600 \mathrm{~km}$. The TB's of FY3B/MWRI from all channels including $\mathrm{PCT}_{36.50}$ and $\mathrm{PCT}_{89.00}$ and TC parameters including TC positions, all named storms with intensity ranging from a tropical depression to category $1-5$ hurricane stages, maximum sustained wind intensity (Vmax) on the satellite overpass time are saved separately. This database currently includes global TCs that were observed by the MWRI satellite from 2011 to 2016. A processing flowchart of the FY3B/MWRI tropical cyclones passive microwave brightness temperature (TCsBT) database from MWRI L1 data is shown in Figure 2.

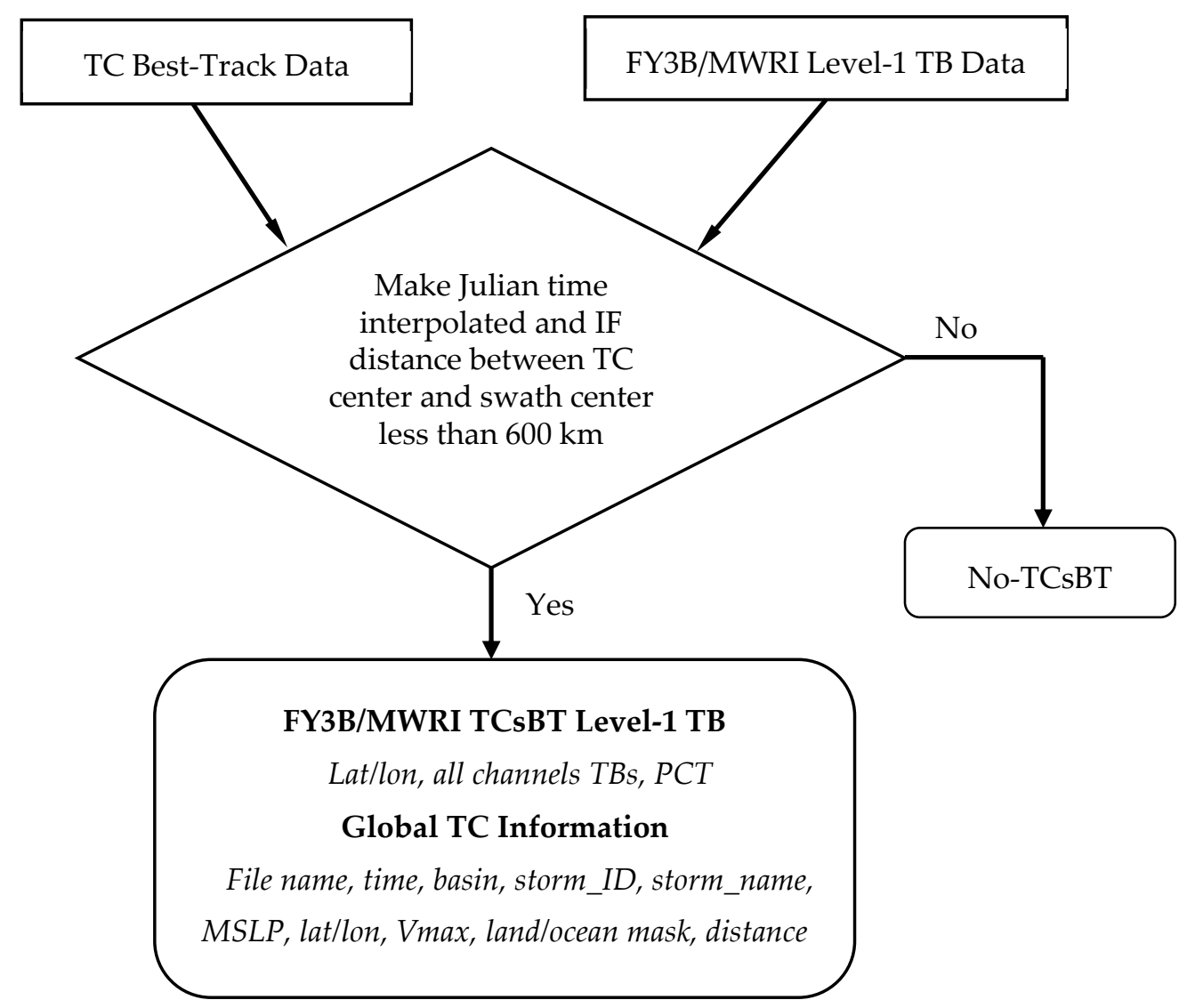

Figure 2. FY-3B/MWRI-based tropical cyclones passive microwave brightness temperature (TCsBT) database construction flowchart. 


\subsection{Selection of MWRI Overpasses}

The dataset applied in this study is derived from the TCsBT database, with 4039 TC orbits obtained from MWRI observations from 2011-2016. Distances between the TC center and the MWRI swath center and corresponding orbit numbers are indicated in different colors (Figure 3). Figure 4 presents a demonstration example of MWRI all-channel TB distribution and $\mathrm{PCT}_{36.50}, \mathrm{PCT}_{89.00}$ produced by the MWRI TCsBT database for hurricane Jimena (EPA201513) in the EPA basin.

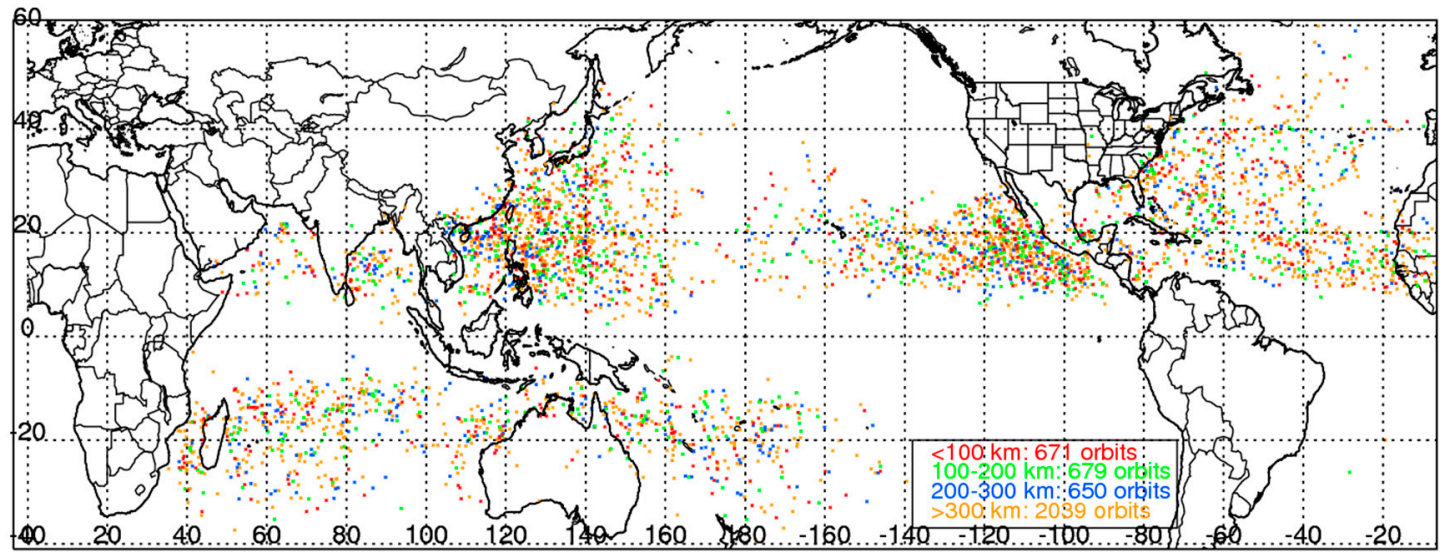

Figure 3. Geographic distribution of TC observations from 2011 to 2016 in the FY3B/MWRI TCsBT database. The number of orbits is provided in the legend.
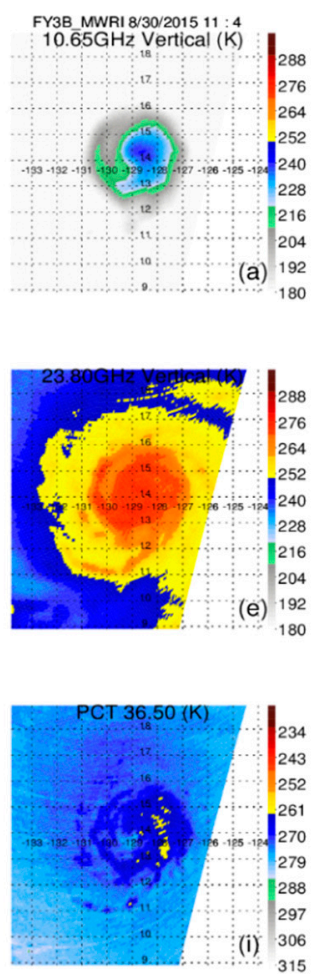
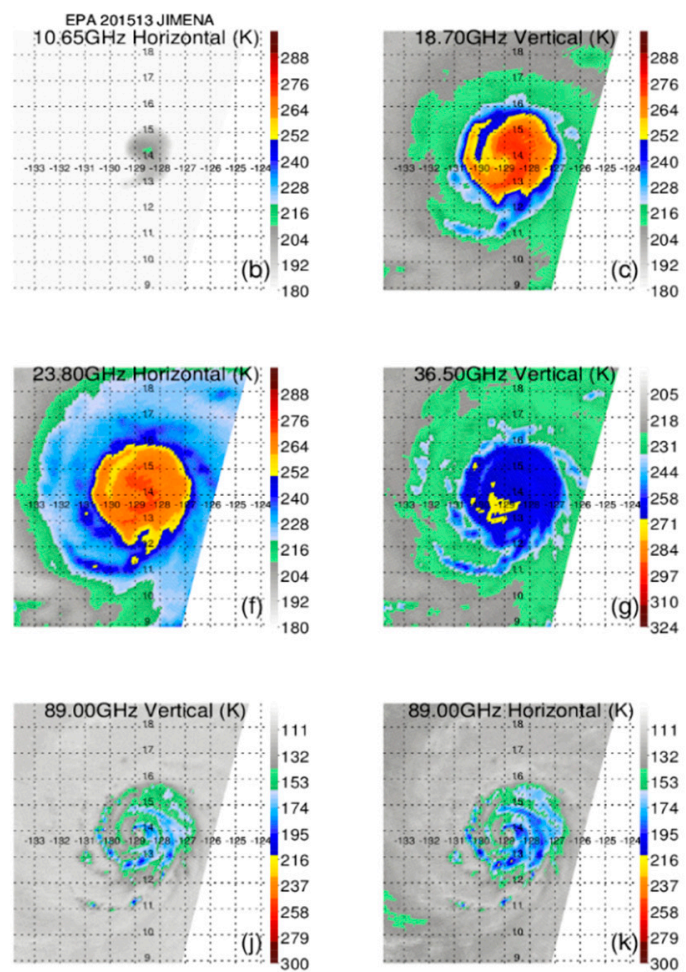
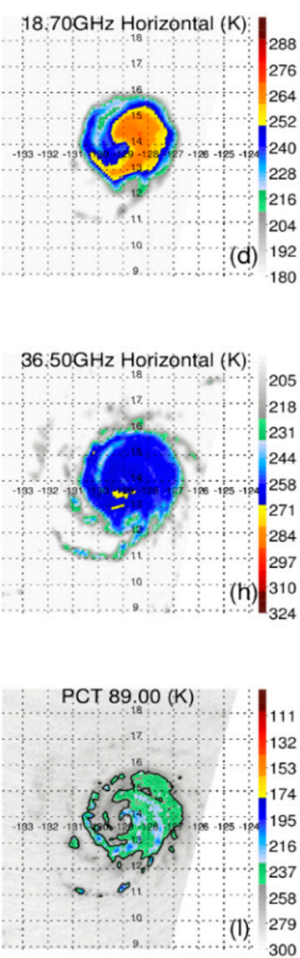

Figure 4. An example demonstration of hurricane Jimena MWRI TB in 30 Aug, 2015 produced from the FY-3B/MWRI TCsBT database for (a) $10.65 \mathrm{GHz}$ vertical polarization, (b) $10.65 \mathrm{GHz}$ horizontal polarization, (c) $18.70 \mathrm{GHz}$ vertical polarization, (d) $18.70 \mathrm{GHz}$ horizontal polarization, (e) $23.80 \mathrm{GHz}$ vertical polarization, (f) $23.80 \mathrm{GHz}$ horizontal polarization, (g) $36.50 \mathrm{GHz}$ vertical polarization, (h) $36.50 \mathrm{GHz}$ horizontal polarization, (i) $\mathrm{PCT}_{36.50}$, (j) $89.00 \mathrm{GHz}$ vertical polarization, (k) $89.00 \mathrm{GHz}$ horizontal polarization, and (1) $\mathrm{PCT}_{89.00}$. 


\section{Results}

\subsection{Relations between PMW TB and TC Intensities}

To examine the relationship between TB and TC intensity, according to the Saffir-Simpson category (see https://www.weather.gov/mfl/saffirsimpson), the four intensity classes used in this study are tropical depression (TD $<34 \mathrm{kt}$ ), tropical storms (34 kt $<\mathrm{TS}<63 \mathrm{kt}$ ), category 1-2 hurricane-strength systems (64 kt < CAT12 $\leq 95 \mathrm{kt}$ ), and category 3-5 systems (CAT35 > $96 \mathrm{kt}$ ).

Figure 5 presents the azimuthal mean TB of 12 variables with different TC intensity classes over all the ocean basins within a $250 \mathrm{~km}$ radial distance from the TC center. Although this size was determined arbitrarily, Fujii [20] showed that the radii of maximum wind speed are smaller than $300 \mathrm{~km}$ (i.e., mature or extratropical transition stage), suggesting that this size would be reasonable. The position (latitude and longitude) of the TC center at satellite observation time is calculated by interpolating from position data from the best-track datasets. The maximum wind speed within the hurricane system usually occurs in the eyewall region [12]. Hoshino et al [8] found that microwave TB of TCs in the 50-100 km annular region has a high correlation with Vmax. Therefore, every $50 \mathrm{~km}$ annular distance from the TC center to radial distance of $250 \mathrm{~km}$ was selected in this study and the mean TB was calculated based on the four TC intensity categories. The changes of each MWRI channel TB and $\mathrm{PCT}_{36.50}, \mathrm{PCT}_{89.00}$ with a $250 \mathrm{~km}$ radial distance were then obtained. Figure 5 shows that at different radial distances, as the TC intensity increases, the TB for 10.65, 18.70, 23.80, 36.50 GHz also increases, with the most rapid increases occurring closer to the 50-100 km TC center. The greater the TC intensity, the clearer the decrease in TB. For $\mathrm{PCT}_{36.50}$ and $\mathrm{PCT}_{89.00}$, at different radial distances, $\mathrm{PCT}_{36.50}$ and $\mathrm{PCT}_{89.00}$ decrease continuously with the increase of TC intensity and gradually increase with the increase of radial distance. The greater the TC intensity, the clearer the TB increase. So, in the range of $250 \mathrm{~km}$ radial distance of the inner core, the TB for the MWRI channels is positively correlated with TC intensity, whereas the $\mathrm{PCT}_{36.50}$ and $\mathrm{PCT}_{89.00}$ are negatively correlated.
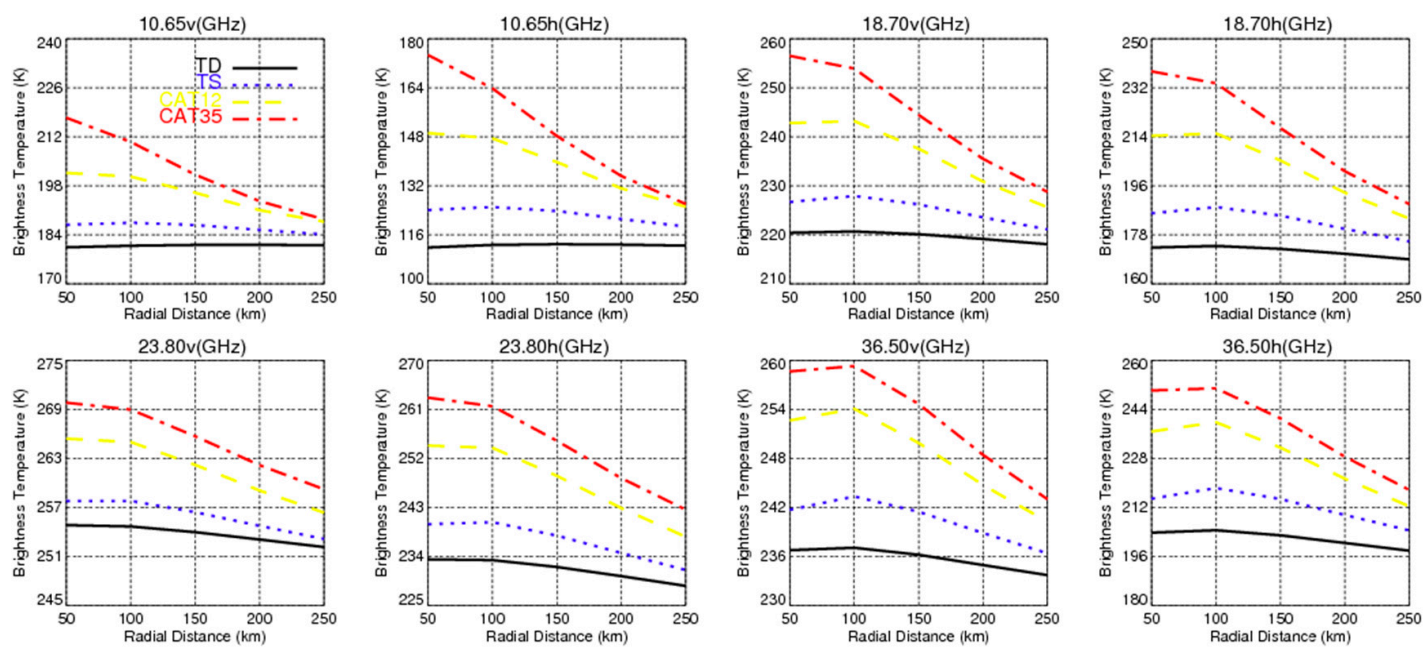

$89.00 v(\mathrm{GHz})$
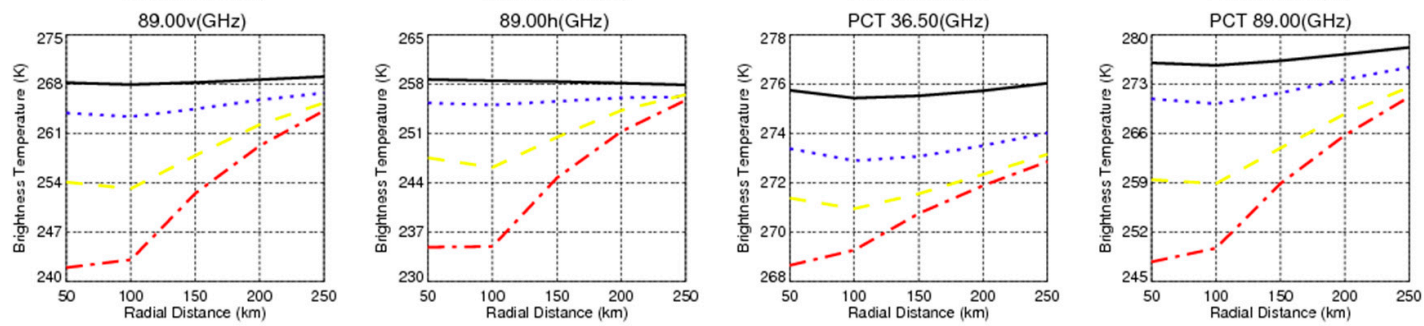

Figure 5. Azimuthal mean TB of MWRI of all channels, $\mathrm{PCT}_{36.50}$ and $\mathrm{PCT}_{89.00}$ over all the ocean basins within $250 \mathrm{~km}$ radial distance with 50km intervals. The legend TD, TS, CAT12 and CAT35 stand for mean TB of a tropical depression, tropical storm, category 1-2 hurricane-strength systems, and category 3-5 hurricane-strength systems in the radial distance with $50 \mathrm{~km}$ intervals, respectively. 
However, it is necessary to choose an optimal radius area for TC intensity estimation. Figure 6 plots the correlation coefficients between the 12 variables and Vmax as a function of the inner core radius area choices. The correlation coefficients are not highly sensitive to the inner core radius choices; however, we found that the highest multiple linear correlation coefficients are achieved when using $100 \mathrm{~km}$ as the inner core radius. Five options for the inner core annular area $(0-50,50-100,100-150$, 150-200, and 200-250 km) are tested to calculate the correlation coefficients between the 12 variables and Vmax (Figure 6).

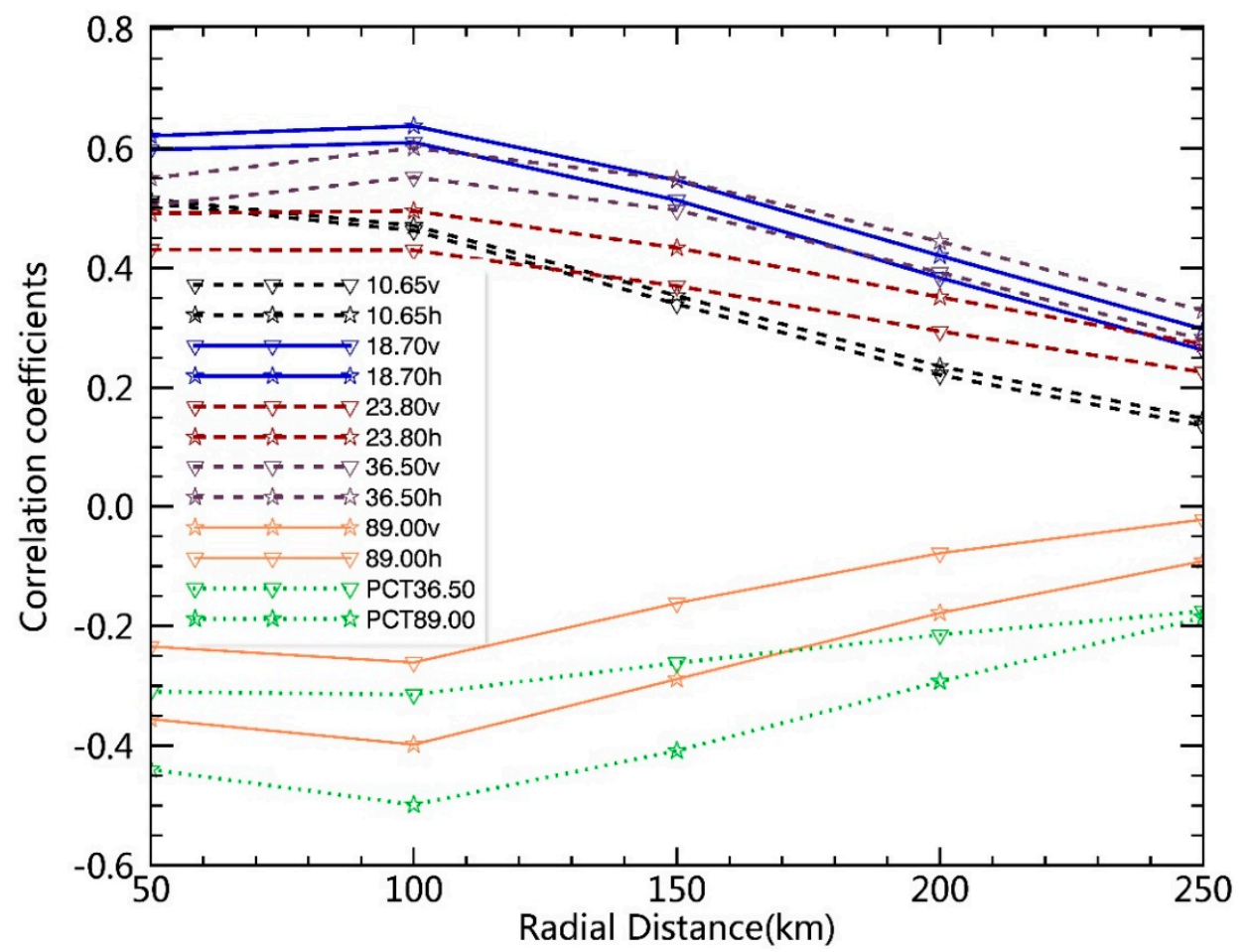

Figure 6. Linear correlation coefficients of maximum sustained wind intensity (Vmax) and MWRI channel TB for every $50 \mathrm{~km}$ interval within a $250 \mathrm{~km}$ radial distance over all the ocean basins using 2011-2016 MWRI data.

The 10.65 GHz mean polarized TB is positively correlated with Vmax, with the highest linear correlation coefficient at $0-50 \mathrm{~km}$, and the linear correlation of horizontal polarization is better than vertical polarization. The mean polarization TBs of $18.70,23.80$, and $36.50 \mathrm{GHz}$ are positively correlated with Vmax, and the linear correlation coefficient is highest in the 50-100 km annular region. The linear correlation coefficients of horizontal polarization are larger than those of vertical polarization. $\mathrm{PCT}_{36.50}$ and $\mathrm{PCT}_{89.00}$ are negatively correlated with Vmax. The negative linear correlation coefficient is highest in the $50-100 \mathrm{~km}$ annular area. The correlation between $89.00 \mathrm{GHz}$ vertical polarization and Vmax is better than that of horizontal polarization. The correlation between $\mathrm{PCT}_{89.00}$ and $\mathrm{Vmax}$ is better than that of $\mathrm{PCT}_{36.50}$.

Based on the above analysis, the $50-100 \mathrm{~km}$ annular area is selected as the study area to estimate the TC intensity. In Section 3.2, a multiple regression model between FY-3B/MWRI TBs and Vmax over the $50-100 \mathrm{~km}$ annular area of TC is established to estimate TC intensity.

Figure 7 presents the cumulative distribution function (CDF) of TB's of all channels and $\mathrm{PCT}_{36.50}$ and $\mathrm{PCT}_{89.00}$ over the 50-100 km annular region. For the 10.65, 18.70, 23.80, and 36.50 GHz channels, the stronger the TC intensity, the higher the TB values are. The higher TB values in these low-frequency channels are due to the radiation from the liquid water or water vapor emission from the TC inner core region. The higher the TC intensity, the stronger the inner core rain is, which is reflected in the CDF results. Conversely, the weaker the TC intensity, the higher the $89 \mathrm{GHz} \mathrm{TB}^{\prime}$ s and $\mathrm{PCT}_{36.50}$ and $\mathrm{PCT}_{89.00}$. 
The $89.00 \mathrm{GHz}$ TB's, $\mathrm{PCT}_{36.50}$ and $\mathrm{PCT}_{89.00}$, are indicating the ice scattering signature in the inner core. The larger the amount of ice and the deeper the convection is in the inner, the lower the values are in these parameters. This results are consistent with many previous studies [8,18].

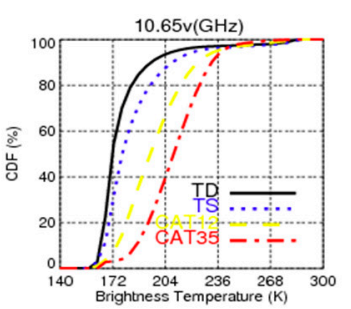

$23.80 \mathrm{v}(\mathrm{GHz})$
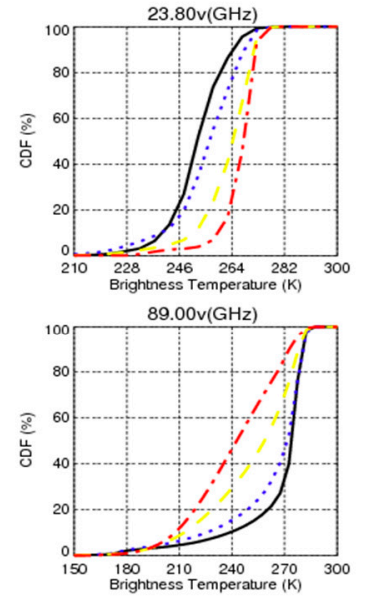

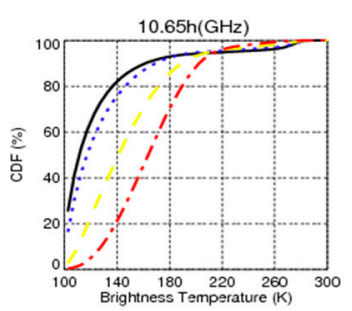

$23.80 \mathrm{~h}(\mathrm{GHz})$

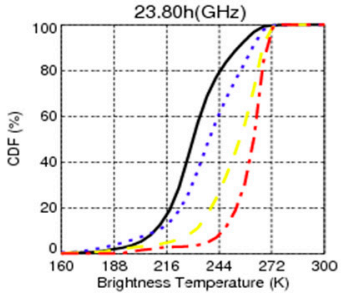

$89.00 \mathrm{~h}(\mathrm{GHz})$

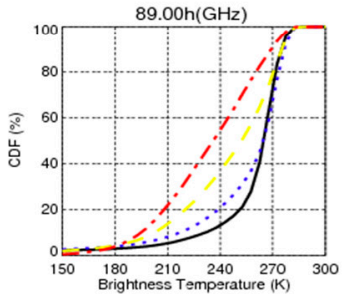

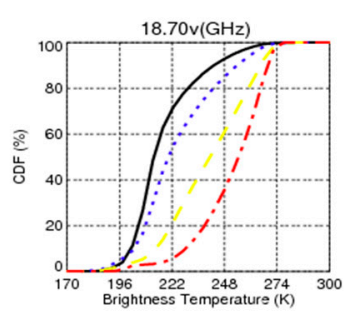

$36.50 \mathrm{v}(\mathrm{GHz})$

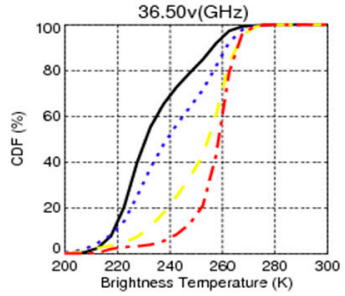

РСТ 36.50

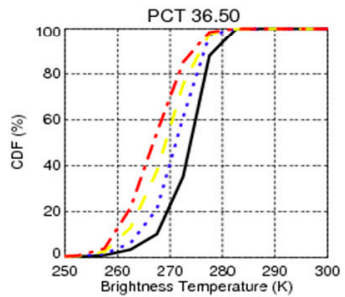

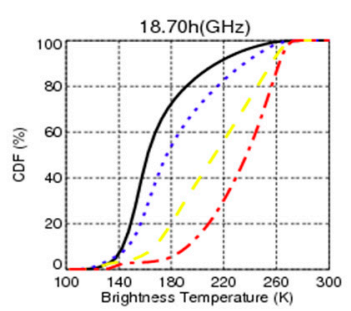

$36.50 \mathrm{~h}(\mathrm{GHz})$
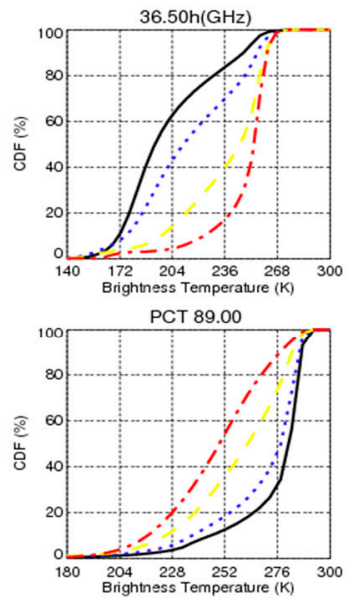

Figure 7. Cumulative distribution function (CDF) of MWRI of all channels TB and $\mathrm{PCT}_{36.50}$ and $\mathrm{PCT}_{89.00}$ over the 50-100 km annular region using the 2011-2016 MWRI data. The legend TD, TS, CAT12, and CAT35 stand for the mean TB of the tropical depression, tropical storm, category 1-2 hurricane-strength systems, and category 3-5 hurricane-strength systems in the radial distance with $50 \mathrm{~km}$ intervals, respectively.

\subsection{TC Intensity Estimation Based on the FY-3B/MWRI TCsBT Database}

\subsubsection{Selection of Variables and Regression Model}

To estimate the TC intensity, PMW variables that are well correlated with TC intensity Vmax need to be determined. In this study, 12 variables over the $50-100 \mathrm{~km}$ annular region in the TC inner core are considered. Although the storm inner-core size is generally defined as within $100 \mathrm{~km}$ from the TC center $[17,18]$, it actually varies between TCs. We consider five areas of the inner core annular region $(50,100,150,200$, and $250 \mathrm{~km}$ ) to calculate the linear correlation coefficients between these variables and Vmax and the result shows that the 50-100 km annular region is optimal to estimate TC intensities (see Figure 6). Table 2 lists 12 variable names in the 50-100 km annular region derived from PMW observations. These variables are used as candidate estimators of TC intensity. Therefore, we use the 50-100 km annular region to calculate the variables listed in Table 3 for the model development verification described in the following sections. However, it is necessary to choose a group of optimal variables from the set of 12 variables to develop the regression model for TC intensity estimation. As stated in Franke [21], multicollinearity is a problem and should be avoided for multilinear regressions. Predictor variables that are highly correlated could cause overfitting problems. Therefore, for each regression model, a correlation coefficient matrix among all the candidate variables is calculated (Table 3). Considering the correlation between channels, especially under different polarization modes of the same channel, the TB correlation is often very high. Therefore, those variables with a correlation coefficient greater than 0.8 will be reviewed to be eliminated when the multiple regression model is established. 
Table 2. List of the 12 variables (units: K) in the inner core annular region derived from PMW observations.

\begin{tabular}{ccc}
\hline \multicolumn{2}{c}{ Variables } & Description \\
\hline 1 & $10.65 \mathrm{v}$ & $10.65 \mathrm{GHz}$ vertical polarization TB \\
2 & $10.65 \mathrm{~h}$ & $10.65 \mathrm{GHz}$ horizontal polarization TB \\
3 & $18.70 \mathrm{v}$ & $18.70 \mathrm{GHz}$ vertical polarization $\mathrm{TB}$ \\
4 & $18.70 \mathrm{~h}$ & $18.70 \mathrm{GHz}$ horizontal polarization TB \\
5 & $23.80 \mathrm{v}$ & $23.80 \mathrm{GHz}$ vertical polarization TB \\
6 & $23.80 \mathrm{~h}$ & $23.80 \mathrm{GHz}$ horizontal polarization TB \\
7 & $36.50 \mathrm{v}$ & $36.50 \mathrm{GHz}$ vertical polarization TB \\
8 & $36.50 \mathrm{~h}$ & $36.50 \mathrm{GHz}$ horizontal polarization TB \\
9 & $89.00 \mathrm{v}$ & $89.00 \mathrm{GHz}$ vertical polarization TB \\
10 & $89.00 \mathrm{~h}$ & $89.00 \mathrm{GHz}$ horizontal polarization TB \\
11 & $\mathrm{PCT}_{36.50}$ & $36.50 \mathrm{GHz}$ polarization corrected TB \\
12 & $\mathrm{PCT}_{89.00}$ & $89.00 \mathrm{GHz}$ polarization corrected TB \\
\hline
\end{tabular}

In this study, the stepwise regression method is used to select the optimal variables. Prior to the stepwise regression, the correlations between MWRI channels should be considered. Therefore, for the regression model, a correlation coefficient matrix among all the candidate variables (see Table 3) and correlation coefficients between MWRI channels TB and Vmax and the scatter plots within the 50-100 km annular region (see Figure 8) are calculated and reviewed to eliminate variables that are highly correlated with each other, and select the variables with the best correlation coefficients between MWRI TB and Vmax. Based on this principle, four variables $\left(10.65 \mathrm{~h}, 23.80 \mathrm{v}, 89.00 \mathrm{v}\right.$, and $\left.\mathrm{PCT}_{36.50}\right)$ are reserved for the TC intensity estimation model establishment. For the remaining variables, stepwise regressions using Interactive Data Language (IDL8.7.2, Linux x86_64 m64, (c) 2019, Harris Geospatial Solutions, Inc., US) International Mathematics and Statistics Library (IMSL) software are performed to further filter out variables with little contribution to the model. Based on the stepwise regression results, no variables can be removed. Therefore, $10.65 \mathrm{~h}, 23.80 \mathrm{v}, 89.00 \mathrm{v}$, and $\mathrm{PCT}_{36.50}$ are used as the estimators of TC intensity.
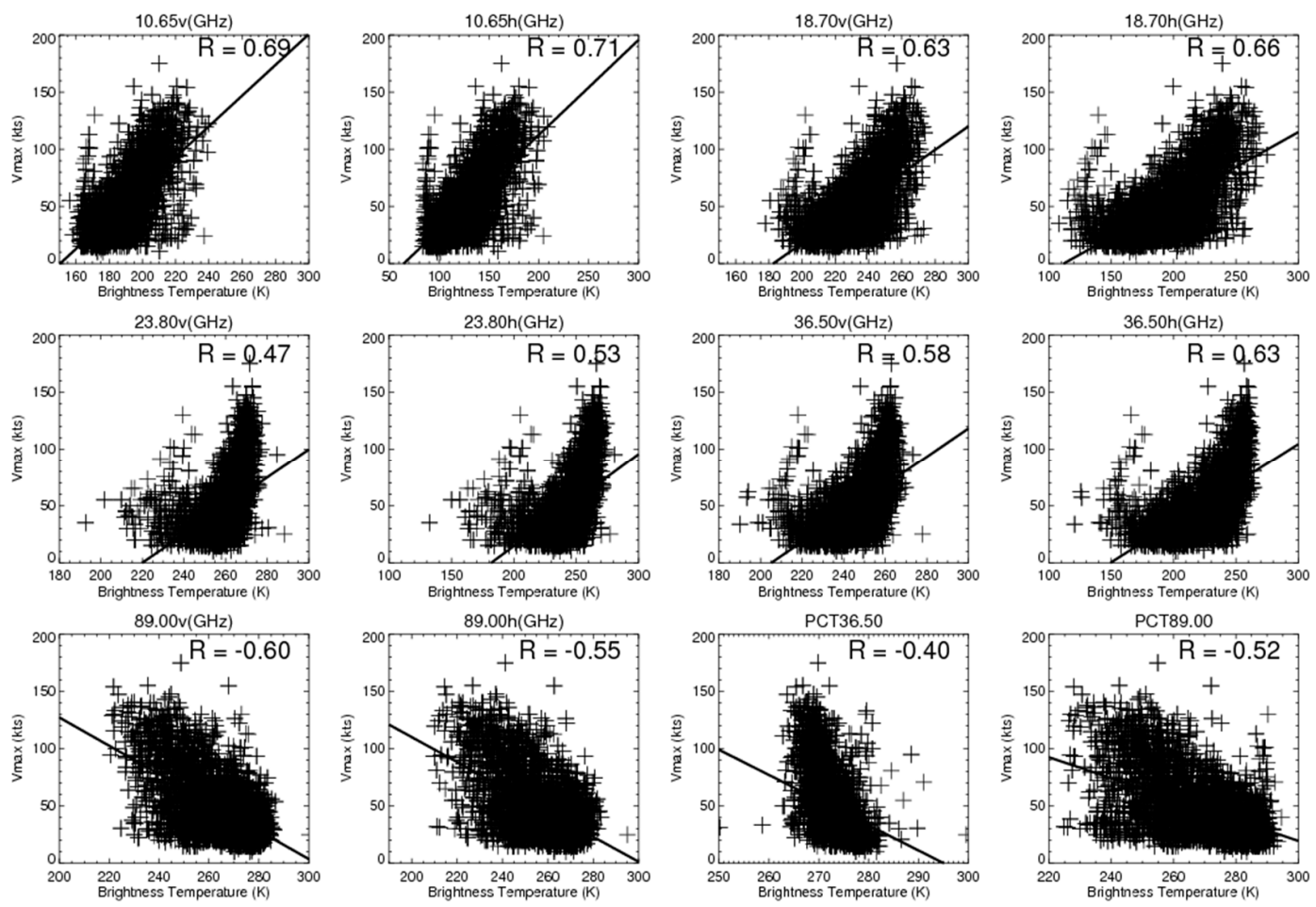

Figure 8. Correlation coefficients between MWRI TB and Vmax, and their scatter plots within the 50-100 km annular region. 
Table 3. Correlation coefficients between the 12 variables in the 50-100 km annular region. All the correlation coefficients over 0.8 to appear in bold font.

\begin{tabular}{|c|c|c|c|c|c|c|c|c|c|c|c|c|}
\hline$R$ & $10.65 v$ & $10.65 \mathrm{~h}$ & $18.70 \mathrm{v}$ & $18.70 \mathrm{~h}$ & $23.80 \mathrm{v}$ & $23.80 \mathrm{~h}$ & $36.50 \mathrm{v}$ & $36.50 \mathrm{~h}$ & $89.00 \mathrm{v}$ & $89.00 \mathrm{~h}$ & $\mathrm{PCT}_{36.50}$ & $\mathrm{PCT}_{89.00}$ \\
\hline $10.65 \mathrm{v}$ & 1.00 & 0.98 & 0.95 & 0.94 & 0.80 & 0.85 & 0.81 & 0.82 & -0.60 & -0.54 & -0.11 & -0.64 \\
\hline $10.65 \mathrm{~h}$ & 0.98 & 1.00 & 0.95 & 0.96 & 0.75 & 0.85 & 0.80 & 0.85 & -0.65 & -0.59 & -0.25 & -0.70 \\
\hline $18.70 \mathrm{v}$ & 0.95 & 0.95 & 1.00 & 0.99 & 0.90 & 0.95 & 0.92 & 0.93 & -0.58 & -0.50 & -0.08 & -0.63 \\
\hline 18.70h & 0.94 & 0.96 & 0.99 & 1.00 & 0.84 & 0.94 & 0.90 & 0.95 & -0.63 & -0.55 & -0.23 & -0.69 \\
\hline $23.80 \mathrm{v}$ & 0.80 & 0.75 & 0.90 & 0.84 & 1.00 & 0.96 & 0.94 & 0.86 & -0.23 & -0.15 & 0.29 & -0.29 \\
\hline $23.80 \mathrm{~h}$ & 0.85 & 0.85 & 0.95 & 0.94 & 0.96 & 1.00 & 0.96 & 0.95 & -0.40 & -0.30 & 0.02 & -0.47 \\
\hline $36.50 \mathrm{v}$ & 0.81 & 0.80 & 0.92 & 0.90 & 0.94 & 0.96 & 1.00 & 0.97 & -0.32 & -0.22 & 0.09 & -0.40 \\
\hline $36.50 \mathrm{~h}$ & 0.82 & 0.85 & 0.93 & 0.95 & 0.86 & 0.95 & 0.97 & 1.00 & -0.48 & -0.37 & -0.14 & -0.56 \\
\hline $89.00 \mathrm{v}$ & -0.60 & -0.65 & -0.58 & -0.63 & -0.23 & -0.40 & -0.32 & -0.48 & 1.00 & 0.99 & 0.71 & 0.99 \\
\hline $89.00 \mathrm{~h}$ & -0.54 & -0.59 & -0.50 & -0.55 & -0.15 & -0.30 & -0.22 & -0.37 & 0.99 & 1.00 & 0.68 & 0.96 \\
\hline $\mathrm{PCT}_{36.50}$ & -0.11 & -0.25 & -0.08 & -0.23 & 0.29 & 0.02 & 0.09 & -0.14 & 0.71 & 0.68 & 1.00 & 0.72 \\
\hline $\mathrm{PCT}_{89.00}$ & -0.64 & -0.70 & -0.63 & -0.69 & -0.29 & -0.47 & -0.40 & -0.56 & 0.99 & 0.96 & 0.72 & 1.00 \\
\hline
\end{tabular}




\subsubsection{Regression Analysis}

Based on the calculation and analysis described above, a multiple linear regression method was used to estimate the future TC intensity. The final dataset for regression analysis includes 6273 MWRI overpasses of 538 TCs in 2011-2016. It is further separated into dependent and independent samples as shown in Table 4. The dependent samples will be used for model development, while the independent samples will be used for verification. Table 4 shows that the dependent samples include 5063 overpasses of $81 \%$ during 2011-2015, while independent samples include 1201 overpasses of $19 \%$ in 2016. Table 4 also presents the distribution of samples and their percentages for different TC intensity categories.

Table 4. Overpass numbers of MWRI samples and sample percentages for both the dependent (2011-2015) and independent (2016) datasets in different TC intensity categories according to the Saffir-Simpson category for all basins over the ocean.

\begin{tabular}{cccccc}
\hline TC Intensity Categories & \multicolumn{2}{c}{$\begin{array}{c}\text { Dependent } \\
(\mathbf{2 0 1 1 - 2 0 1 5 )}\end{array}$} & \multicolumn{2}{c}{$\begin{array}{c}\text { Independent } \\
\mathbf{( 2 0 1 6 )}\end{array}$} & $\begin{array}{c}\text { All TC Overpasses } \\
(\mathbf{2 0 1 1 - 2 0 1 6 )}\end{array}$ \\
\hline $\begin{array}{c}\text { Tropical depression } \\
\quad(\mathrm{TD}<34 \mathrm{kt})\end{array}$ & 2049 & $82 \%$ & 446 & $18 \%$ & 2495 \\
$\quad \begin{array}{c}\text { Tropical storm } \\
\quad(34<\mathrm{TS}<63 \mathrm{kt})\end{array}$ & 1884 & $80 \%$ & 458 & $20 \%$ & 2342 \\
$\begin{array}{c}\text { Category } 1-2 \text { hurricanes } \\
\quad(64<\text { CAT12 } \leq 95 \mathrm{kt})\end{array}$ & 724 & $80 \%$ & 186 & $20 \%$ & 910 \\
$\begin{array}{c}\text { Category 3-5 hurricanes } \\
\quad \text { (CAT35 }>96 \mathrm{kt})\end{array}$ & 406 & $77 \%$ & 120 & $23 \%$ & 526 \\
$\quad$ All TC overpasses & 5063 & $81 \%$ & 1210 & $19 \%$ & 6273 \\
\hline
\end{tabular}

Table 5 shows the results between TBs and Vmax obtained by the four-parameter multiple regression model. Figure 9 presents the correlation coefficients between estimated 0-h, future 6-h, 12-h, 18-h, 24-h Vmax and best-track Vmax and their scatter plots. Therein, the estimated future 12-h TC intensity is the best correlation with the best-track TC intensity, the correlation coefficient is 0.634 , the average absolute error (MAE) is $14.961 \mathrm{kt}$, and the root mean square error (RMSE) is $21.026 \mathrm{kt}$. The next best correlation is the 6-h TC intensity estimation result. The correlation coefficient of the future 6-h TC intensity estimation is 0.631 , the MAE is $15.034 \mathrm{kt}$, and the RMSE is $20.996 \mathrm{kt}$. Regression models for estimating 12-h future Vmax have a lower MAE than other periods estimating Vmax. Although these estimating Vmax errors are similar in future different periods, our results not only suggest that the satellite data latency can be resolved this way, it also indicates that a higher accuracy might be achieved by using the 12-h future Vmax estimation models.

Table 5. Results for independent estimations of 0-h Vmax and future 6-h, 12-h, 18-h, and 24-h for 2016 Vmax using the $10.65 \mathrm{~h}, 23.80 \mathrm{v}, 89.00 \mathrm{v}$, and $\mathrm{PCT}_{36.50}$ regression model based on 2011-2015 dependent samples. $\mathrm{R}$ is the correlation coefficients, MAE is the mean absolute errors in kt, RMSE is the root mean square error in kt and STD is the standard deviation in kt between independent estimations of Vmax and best-track Vmax.

\begin{tabular}{cccccc}
\hline \multirow{2}{*}{ Results } & \multicolumn{5}{c}{ Vmax } \\
\cline { 2 - 6 } & $\mathbf{0 - h}$ & $\mathbf{6 - h}$ & $\mathbf{1 2 - h}$ & $\mathbf{1 8 - h}$ & $\mathbf{2 4 - h}$ \\
\hline$R$ & 0.602 & 0.631 & 0.634 & 0.619 & 0.594 \\
MAE (kt) & 15.791 & 15.034 & 14.961 & 15.624 & 16.759 \\
RMSE (kt) & 21.621 & 20.996 & 21.026 & 21.799 & 22.936 \\
STD (kt) & 21.593 & 20.972 & 20.979 & 21.726 & 22.819 \\
\hline
\end{tabular}



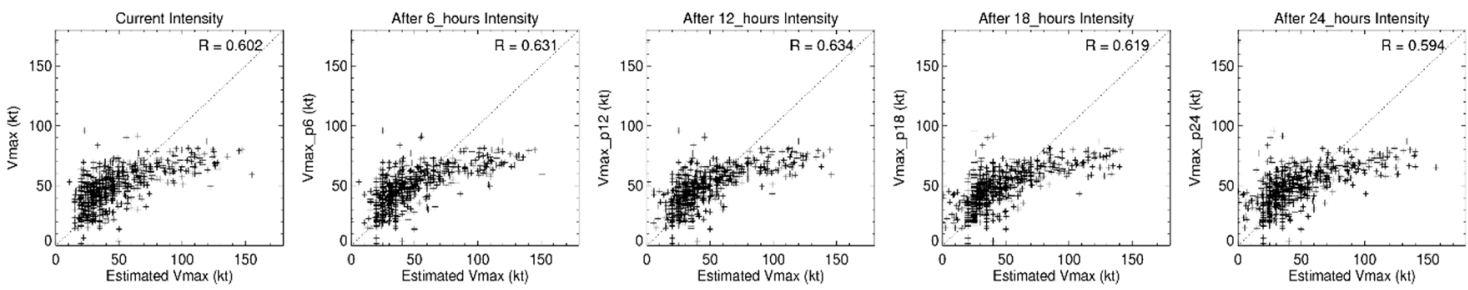

Figure 9. Correlation coefficients between estimated Vmaxand best-track Vmax and their scatter plots. The correlation coefficient of the estimated 0-h, future 6-h, 12-h, 18-h, 24-h Vmax, and best-track Vmax is $0.602,0.631,0.634,0.619$, and 0.594 , respectively.

\subsubsection{Variable Weightiness Contributions}

To determine the weightiness of $10.65 \mathrm{~h}, 23.80 \mathrm{v}, 89.00 \mathrm{v}$, and $\mathrm{PCT}_{36.50}$ versus Vmax estimation in the regression model, a normalized multiple regression algorithm should be established to obtain the normalized regression coefficient of each variable. The corresponding regression coefficient is the contribution weightiness of the variables to TC intensity. Formulas (3)-(7) list the processing algorithms of normalized regression variables and Formula (8) is the normalized multiple regression equation.

$$
\begin{aligned}
& \text { nor_Vmax }=[\operatorname{Vmax}-\operatorname{Mean}(\operatorname{Vmax})] / \operatorname{StdDev}(\mathrm{Vmax}) \\
& \text { nor_10.65h }=[10.65 h-\operatorname{Mean}(10.65 h)] / \operatorname{StdDev}(10.65 h) \\
& \text { nor_23.80v }=[23.80 v-\operatorname{Mean}(23.80 v)] / \operatorname{StdDev}(23.80 v) \\
& n o r \_89.00 v=[89.00 v-\operatorname{Mean}(89.00 v)] / \operatorname{StdDev}(89.00 v) \\
& \text { nor_PCT } 36.50=\left[P C T_{36.50}-\operatorname{Mean}\left(P C T_{36.50}\right)\right] / \operatorname{StdDev}\left(P C T_{36.50}\right) \\
& \text { nor_Vmax }=\text { const }+a \times n o r \_10.65 h+b \times n o r \_23.80 v+c \times n o r \_89.00 v+d \times n o r \_P C T_{36.50}
\end{aligned}
$$

where Mean is the mean value, StdDev is the standard deviation, const is a constant and a, b, c, and d are regression coefficients for four normalized variables in Formula (8), respectively.

Table 6 lists the results calculated by the normalized algorithm. The highest normalized correlation coefficient of 0.691 is between estimated future 12-h Vmax and TB. For the 0-h TC intensity estimation, $\mathrm{PCT}_{36.50}$ has the largest contribution weight, followed by $23.80 \mathrm{v}, 10.65 \mathrm{~h}$, and $89.00 \mathrm{v}$. For future $6-\mathrm{h}$, 12-h, 18-h, and 24-h, 23.80v has the largest contribution weight, followed by $\mathrm{PCT}_{36.50}$.

Table 6. Regression variables and their corresponding normalized coefficients to estimate best-track Vmax and future 6-h, 12-h, 18-h, and 24-h Vmax.

\begin{tabular}{cccccc}
\hline \multirow{2}{*}{\begin{tabular}{c} 
Normalized correlation coefficients \\
\cline { 2 - 5 }
\end{tabular}} & \multicolumn{5}{c}{ Normalized multiple correlation coefficients } \\
\cline { 2 - 6 } $\mathrm{R}$ & $0 \mathrm{~h}$ & $6 \mathrm{~h}$ & $12 \mathrm{~h}$ & $18 \mathrm{~h}$ & $24 \mathrm{~h}$ \\
\cline { 2 - 6 } & 0.653 & 0.679 & 0.691 & 0.687 & 0.671 \\
\hline Normalized regression variables & \multicolumn{5}{c}{ Normalized multiple regression coefficients } \\
coefficients & 0.373 & 0.211 & 0.069 & -0.057 & -0.159 \\
$\mathrm{a}$ & 0.458 & 0.535 & 0.590 & 0.622 & 0.635 \\
$\mathrm{~b}$ & 0.250 & 0.091 & -0.041 & -0.157 & -0.246 \\
$\mathrm{c}$ & -0.481 & -0.457 & -0.429 & -0.392 & -0.352 \\
$\mathrm{~d}$ & & & &
\end{tabular}

\subsubsection{Comparison with other TC Intensity Estimation Techniques}

In this section, a general comparison of error statistics with other existing algorithms estimating TC intensity was provided. Ideally, a homogeneous comparison using a homogeneous dataset is preferred. However, that will cause too much effort and is beyond the scope of this study. Here only a general 
comparison is provided in Table 7 to show MAEs and/or RMSEs of other techniques as published in refereed publications. First, the Dvorak TC intensity estimation technology was represented by Knaff et al. [22] that conducted the systematic verifications of the Dvorak technique to better calibrate Dvorak intensity estimates for tropical cyclone forecast operations. MAE and RSME of estimated Vmax is about 5-10 kt and 6-14 kt based on the Dvorak technique, respectively. Another comparable publication is Bankert et al. [18] that feature-selection algorithm and k-nearest-neighbor technique based on the SSM/I 85GHz h-polarization imagery that was used to estimate TC intensity, and make verification using 2 -h aircraft reconnaissance-based best track data, a root-mean-square error (RMSE) of $19.8 \mathrm{kt}$ is produced. Our error statistics are not as good as the subjective Dvorak technique [22] but are in line with the SSM/I-based algorithm [18]. Still, the multivariate regression algorithm based on PMW multiple TB channels in this study provides additional information in microwave channels that could complement the Dvorak technique used widely in operational centers.

Table 7. Comparison of the error statistics (MAE and RMSE) of TC intensity Vmax of this study and other satellite-based TC intensity estimation methods.

\begin{tabular}{|c|c|c|c|c|c|}
\hline Methods & Sensors & Verification against & MAE & RMSE & Reference \\
\hline Dvorak technique & VIS, IR & $\begin{array}{c}\text { Within 2-h aircraft } \\
\text { reconnaissance-based } \\
\text { best track }\end{array}$ & 5-11 kt & $6-14 \mathrm{kt}$ & $\begin{array}{l}\text { Knaff et al. } \\
\text { (2010) [22] }\end{array}$ \\
\hline $\begin{array}{c}\text { Feature-based } \\
\text { k-nearest-neighbor }\end{array}$ & $\mathrm{SSM} / \mathrm{I}$ & Best track & $14-16 \mathrm{kt}$ & $18.1-19.8 \mathrm{kt}$ & $\begin{array}{l}\text { Bankert and } \\
\text { Tag (2002) [18] }\end{array}$ \\
\hline $\begin{array}{c}\text { PMW multiple channels } \\
\text { TB-based multivariate } \\
\text { regression }\end{array}$ & MWRI & Best track & $14-16 \mathrm{kt}$ & $20-23 \mathrm{kt}$ & This study \\
\hline
\end{tabular}

\section{Summary and Conclusions}

A global TCsBT database based on the 6-year FY-3B/MWRI TB data and corresponding best-track data was developed, and TB distribution related to TC Vmax was presented over the TC center to $250 \mathrm{~km}$ radial distance annular regions. According to correlation analysis, mean TB parameters of 10.65 and $18.70 \mathrm{GHz}$ have a high correlation with TC Vmax and the $50-100 \mathrm{~km}$ annular region is a good representative area for TC intensity estimation. In this study, four predictors $(10.65 \mathrm{~h}, 23.80 \mathrm{v}, 89.00 \mathrm{v}$, and $\mathrm{PCT}_{36.50}$ ) from TCsBT database for 2011-2015 were selected as the optimal combination for TC intensity estimation based on the multiple linear regression method, and independent verification was conducted by using the 2016 Vmax in the TC best-track data.

In previous studies, such as Jiang [12], Cecil and Zipser [13], and Bankert and Tag [18], only $\mathrm{PCT}_{85}$ or $85 \mathrm{GHz}$ is treated as a noticeable parameter in estimating TC intensity because it is widely recognized that $\mathrm{PCT}_{85}$ has good sensitivity to ice particles and is related to the activity of the convective $\mathrm{TC}$ clouds [8]. However, for a high-wind case, $\mathrm{PCT}_{36.50}$ and $\mathrm{PCT}_{89.00}$ may do more harm than good for Vmax estimation because of the influences of precipitation and ice scattering. In this case, lower frequencies such as $10.65 \mathrm{~h}$ may improve the situation for estimating the high winds because lower frequency TB is less affected by clouds and precipitation than higher frequency, and also reflects the wind speed more directly [9]. Although our results are not as good as the subjective Dvorak technique, they are in line with other TC intensity algorithms, such as Bankert and Tag (2002) SSM/I-based Feature-based k-nearest-neighbor TC intensity algorithm. Meanwhile, our study shows that parameters from MWRI lower frequencies are also highly correlated with TC intensity (Figures 6 and 9). Moreover, other frequency parameters such as $23.80 \mathrm{v}, 89.00 \mathrm{v}$, and $\mathrm{PCT}_{36.50}$ are not negligible since they provide additional information in microwave channels that can be used for TC intensity estimation and they also play an important role in the TC intensity estimation. The TC intensity estimation algorithm based on these additional microwave channels could complement the Dvorak technique used widely in operational centers and needs to be further investigated and explored in the future. 
This study focuses on all TC-prone basins. There are many differences in TC characteristics among basins, and therefore, different candidate parameters for different basins may be required for future multiple regression TC intensity estimations. In this study, satellite microwave level-1 TB data are taken from a single remote sensor (FY-3B/MWRI). Although the performance and data quality of microwave sensors has improved continuously in recent years, the errors of TC intensity estimation still vary among sensors. It is, therefore, necessary in future to develop different TC intensity estimation techniques to reduce the errors of TC intensity estimation. Multi-source remote sensors or satellites for synchronous observation of TCs will provide more diversified information, which will undoubtedly provide stronger support for the establishment of an objective TC intensity estimation model. Estimation of TC intensity using microwave sensors can be conducted in the meantime, which can provide objectively analyzed TC information to complement traditionally-used Dvorak analysis.

Author Contributions: Conceptualization: B.Q. and H.J.; Data curation: Y.W.; Funding acquisition: F.W.; Investigation: F.W.; Methodology: B.Q. and H.J.; Project administration: F.W.; Resources: H.J. and F.W.; Software: B.Q. and H.J.; Supervision: H.J. and F.W.; Visualization: B.Q.; Writing-original draft: B.Q. and Y.W.; Writing-review \& editing: H.J., F.W., and Y.W. All authors have read and agreed to the published version of the manuscript.

Funding: This research was supported by the National Key Research and Development Program of China “Development of Meteorological Satellite Remote Sensing Technology and Platform for Global Monitoring, Assessments and Applications" under the funding code of 2018YFC1506500 and Jiangsu basic research program youth fund project of China, Grant BK20150911.

Acknowledgments: This work was conducted during the first author's 1-yr visit at FIU under the supervision of the second author. The authors thank Yongxian Pei, Xinxi Wang from FIU and Xiang Wang from NUIST for their helpful discussions and satellite data processing. The authors really appreciate the constructive comments from three anonymous reviewers that contribute greatly in improving the manuscript.

Conflicts of Interest: The authors declare no conflict of interest.

\section{References}

1. Dvorak, V.F. Tropical Cyclone Intensity Analysis and Forecasting from Satellite Imagery. Mon. Weather Rev. 1975, 103, 420-430. [CrossRef]

2. Velden, C.S.; Olander, T.L.; Zehr, R.M. Development of an Objective Scheme to Estimate Tropical Cyclone Intensity from Digital Geostationary Satellite Infrared Imagery. Weather Forecast. 1998, 13, 172-186. [CrossRef]

3. Olander, T.L.; Velden, C.S. The Advanced Dvorak Technique: Continued Development of an Objective Scheme to Estimate Tropical Cyclone Intensity Using Geostationary Infrared Satellite Imagery. Weather Forecast. 2007, 22, 287-298. [CrossRef]

4. Olander, T.L.; Velden, C.S. The UW-CIMMS Advanced Dvorak Technique (ADT): Current status and future upgrades. In Proceedings of the 33rd Conference on Hurricanes and Tropical Meteorology, Ponte Verdi, FL, USA, 18-20 April 2018; p. 247.

5. Yoshida, S.; Sakai, M.; Shouji, A.; Hirohata, M.; Shimizu, A. Estimation of Tropical Cyclone Intensity Using Aqua/AMSR-E Data. RSMC Tokyo Typhoon Cent. Tech. Rev. 2011, 13, 1-36.

6. Hawkins, J.D.; Lee, T.F.; Richardson, K.; Sampson, C.; Turk, F.J.; Kent, J.E. Satellite multi-sensor tropical cyclone structure monitoring. Bull. Am. Meteorol. Soc. 2001, 82, 567-578. [CrossRef]

7. Lee, T.F.; Turk, F.J.; Hawkins, J.; Richardson, K. Interpretation of TRMM TMI Images of Tropical Cyclones. Earth Interact. 2002, 6, 1-17. [CrossRef]

8. Hoshino, S.; Nakazawa, T. Estimation of Tropical Cyclone's Intensity Using TRMM/TMI Brightness Temperature Data. J. Meteorol. Soc. Jpn. 2007, 85, 437-454. [CrossRef]

9. Yan, B.; Weng, F. Applications of AMSR-E measurements for tropical cyclone predictions Part I: Retrieval of Sea Surface Temperature and Wind speed. Adv. Atmos. Sci. 2008, 25, 227-245. [CrossRef]

10. Jiang, H.; Zagrodnik, J.P.; Tao, C.; Zipser, E.J. Classifying Precipitation Types in Tropical Cyclones Using the NRL 37 GHz Color Product. J. Geophys. Res. Atmos. 2018, 123, 5509-5524. [CrossRef]

11. Weng, F.; Grody, N.C. Retrieval of cloud liquid water using the special sensor microwave imager (SSM/I). J. Geophys. Res. Space Phys. 1994, 99, 25535-25551. [CrossRef] 
12. Jiang, H.; Tao, C.; Pei, Y. Estimation of Tropical Cyclone Intensity in the North Atlantic and North Eastern Pacific Basins Using TRMM Satellite Passive Microwave Observations. J. Appl. Meteorol. Climatol. 2019, 58, 185-197. [CrossRef]

13. Cecil, D.J.; Zipser, E.J. Relationships between Tropical Cyclone Intensity and Satellite-Based Indicators of Inner Core Convection: 85-GHz Ice-Scattering Signature and Lightning. Mon. Weather Rev. 1999, 127, 103-123. [CrossRef]

14. Spencer, R.W.; Goodman, H.M.; Hood, R.E. Precipitation Retrieval over Land and Ocean with the SSM/I: Identification and Characteristics of the Scattering Signal. J. Atmos. Ocean. Technol. 1989, 6, 254-273. [CrossRef]

15. Grody, N.C. Remote sensing of the atmosphere from satellites using microwave radiometry. In Atmospheric Remote Sensing by Microwave Radiometry; John Wiley: New York, NY, USA, 1993; pp. 259-304.

16. Glass, M.; Felde, G.W. Intensity estimation of tropical cyclones using SSM/I brightness temperatures. In Proceedings of the Preprints, Sixth Conference on Satellite Meteorology and Oceanography, Atlanta, GA, USA, 5-10 January 1992; pp. J8-J10.

17. Rao, G.V.; MacArthur, P.D. The SSM/I Estimated Rainfall Amounts of Tropical Cyclones and Their Potential in Predicting the Cyclone Intensity Changes. Mon. Weather Rev. 1994, 122, 1568-1574. [CrossRef]

18. Bankert, R.L.; Tag, P.M. An Automated Method to Estimate Tropical Cyclone Intensity Using SSM/I Imagery. J. Appl. Meteorol. 2002, 41, 461-472. [CrossRef]

19. Landsea, C.W.; Franklin, J.L. Atlantic Hurricane Database Uncertainty and Presentation of a New Database Format. Mon. Weather Rev. 2013, 141, 3576-3592. [CrossRef]

20. Fujii, T. Statistical Analysis of the Characteristics of Severe Typhoons Hitting the Japanese Main Islands. Mon. Weather Rev. 1998, 126, 1091-1097. [CrossRef]

21. Franke, G.R. Multicollinearity. In Wiley International Encyclopedia of Marketing; Sheth, J., Malhotra, N., Eds.; JohnWiley \& Sons Ltd.: Hoboken, NJ, USA, 2010. [CrossRef]

22. Knaff, J.A.; Brown, D.P.; Courtney, J.; Gallina, G.M.; Beven, J.L. An Evaluation of Dvorak Technique-Based Tropical Cyclone Intensity Estimates. Weather Forecast. 2010, 25, 1362-1379. [CrossRef]

(C) 2020 by the authors. Licensee MDPI, Basel, Switzerland. This article is an open access article distributed under the terms and conditions of the Creative Commons Attribution (CC BY) license (http://creativecommons.org/licenses/by/4.0/). 